\title{
COVID-19 and Neonatal Respiratory Care: Current Evidence and Practical Approach
}

\author{
${ }^{1}$ Neonatal Division, Department of Pediatrics, McGill University \\ Health Center, Montreal, Quebec, Canada \\ 2 Department of Pediatrics, UC Davis, Sacramento, California \\ ${ }^{3}$ Department of Pediatrics and Neonatology, University Hospital \\ Degli Infermi, Biella, Italy \\ ${ }^{4}$ Department of Pediatrics, Women and Infants Hospital, Brown \\ University, Providence, Rhode Island
}

Wissam Shalish, MD ${ }^{1}$ Satyanarayana Lakshminrusimha, $\mathrm{MD}^{2}$ Paolo Manzoni, MD ${ }^{3}$ Martin Keszler, MD ${ }^{4}$ Guilherme M. Sant'Anna, MD, PhD, FRCPC ${ }^{1}$

Am J Perinatol 2020;37:780-791.
Address for correspondence Guilherme M. Sant'Anna, MD, PhD, FRCPC, Neonatal Division, Department of Pediatrics, McGill University Health Center, 1001 Décarie Boulevard, Room 05.2711,

Montreal H4A 3J1, Canada (e-mail: guilherme.santanna@mcgill.ca).

\section{Abstract}

Keywords

- neonatal respiratory care

- neonatal COVID-19

- aerosol-generating procedures
The novel coronavirus disease 2019 (COVID-19) pandemic has urged the development and implementation of guidelines and protocols on diagnosis, management, infection control strategies, and discharge planning. However, very little is currently known about neonatal COVID-19 and severe acute respiratory syndrome-coronavirus-2 (SARS-CoV-2) infections. Thus, many questions arise with regard to respiratory care after birth, necessary protection to health care workers (HCW) in the delivery room and neonatal intensive care unit (NICU), and safety of bag and mask ventilation, noninvasive respiratory support, deep suctioning, endotracheal intubation, and mechanical ventilation. Indeed, these questions have created tremendous confusion amongst neonatal HCW. In this manuscript, we comprehensively reviewed the current evidence regarding COVID-19 perinatal transmission, respiratory outcomes of neonates born to mothers with COVID-19 and infants with documented SARSCoV-2 infection, and the evidence for using different respiratory support modalities and aerosol-generating procedures in this specific population. The results demonstrated that to date, neonatal COVID-19 infection is uncommon, generally acquired postnatally, and associated with favorable respiratory outcomes. The reason why infants display a milder spectrum of disease remains unclear. Nonetheless, the risk of severe or critical illness in young patients exists. Currently, the recommended respiratory approach for infants with suspected or confirmed infection is not evidence based but should include all routinely used types of support, with the addition of viral filters, proper personal protective equipment, and placement of infants in isolation rooms, ideally with negative pressure. As information is changing rapidly, clinicians should frequently watch out for updates on the subject.

Key Points

- Novel coronavirus disease 2019 (COVID-19) pandemic urged development of guidelines.

- Neonatal COVID-19 disease is uncommon.

- Respiratory outcomes in neonates seems favorable.

- Current neonatal respiratory care should continue.

received

April 17, 2020

accepted after revision

April 17, 2020

published online

May 2, 2020
Copyright (c) 2020 by Thieme Medical

Publishers, Inc., 333 Seventh Avenue,

New York, NY 10001, USA

Tel: +1(212) 760-0888
DOI https://doi.org/

10.1055/s-0040-1710522.

ISSN 0735-1631. 
As of April 12, 2020, the World Health Organization (WHO) had reported nearly 1.7 million people, including thousands of health care workers (HCW), infected with novel coronavirus disease 2019 (COVID-19) worldwide. In response to the pandemic, hospitals have quickly ramped up efforts to develop and implement guidelines and protocols. These contingency plans have focused on diagnosis, treatment, discharge, and infection control strategies, but preparation and dissemination have been challenged due to paucity of high-quality evidence, rapid pace of new information, and conflicting data. Neonatal intensive care units (NICUs) have been relatively spared so far, and thus very little is currently known about neonatal severe acute respiratory syndrome-coronavirus-2 (SARS-CoV-2) infection. Many questions pertaining to the newborn population have arisen, particularly with regard to their respiratory care. What are the chances of vertical transmission of the virus and how should the infant be managed during the immediate postpartum period? What is the optimal management of a preterm infant born to a SARS-CoV-2 positive mother requiring respiratory support immediately after birth? How should HCW protect themselves? What is the optimal approach for managing an extremely preterm infant already on continuous positive airway pressure (CPAP) that develops signs and symptoms suspicious for COVID-19? Can this patient still be safely managed with noninvasive support? If the patient deteriorates, are procedures, such as mask ventilation or deep suctioning, safe or should the infant be immediately intubated? Altogether, these scenarios have created tremendous confusion amongst neonatal HCW ( - Fig. 1). These anxieties have been exacerbated further by an inability to simply extrapolate current adult recommendations to neonates, given their remarkably different respiratory physiology and the course itself of COVID-19 disease.

Therefore, we formed an ad hoc working group to develop guidelines on neonatal respiratory care during the COVID-19 outbreak. We comprehensively reviewed the available evidence regarding perinatal transmission of the virus, respiratory outcomes of neonates born to mothers with COVID-19 and those infants with documented SARS-CoV-2 infection, as well as the evidence for using different respiratory support modalities, and aerosol-generating procedures (AGPs) in this specific population. Based on the available data, we provide a practical approach for their respiratory management.

\section{Clinical Features and Outcomes}

For the literature review, we searched for all studies published between December 1, 2019 and April 12, 2020 using the PubMed search engine, SciELO database, and Google scholar. Search terms included (COVID-19 or SARS-CoV-2) AND (neonate or newborn or infant or pregnancy). Two authors (W.S. and G.S.) reviewed all studies and further retrieved additional articles through reference searching and personal communication. All case reports, case series

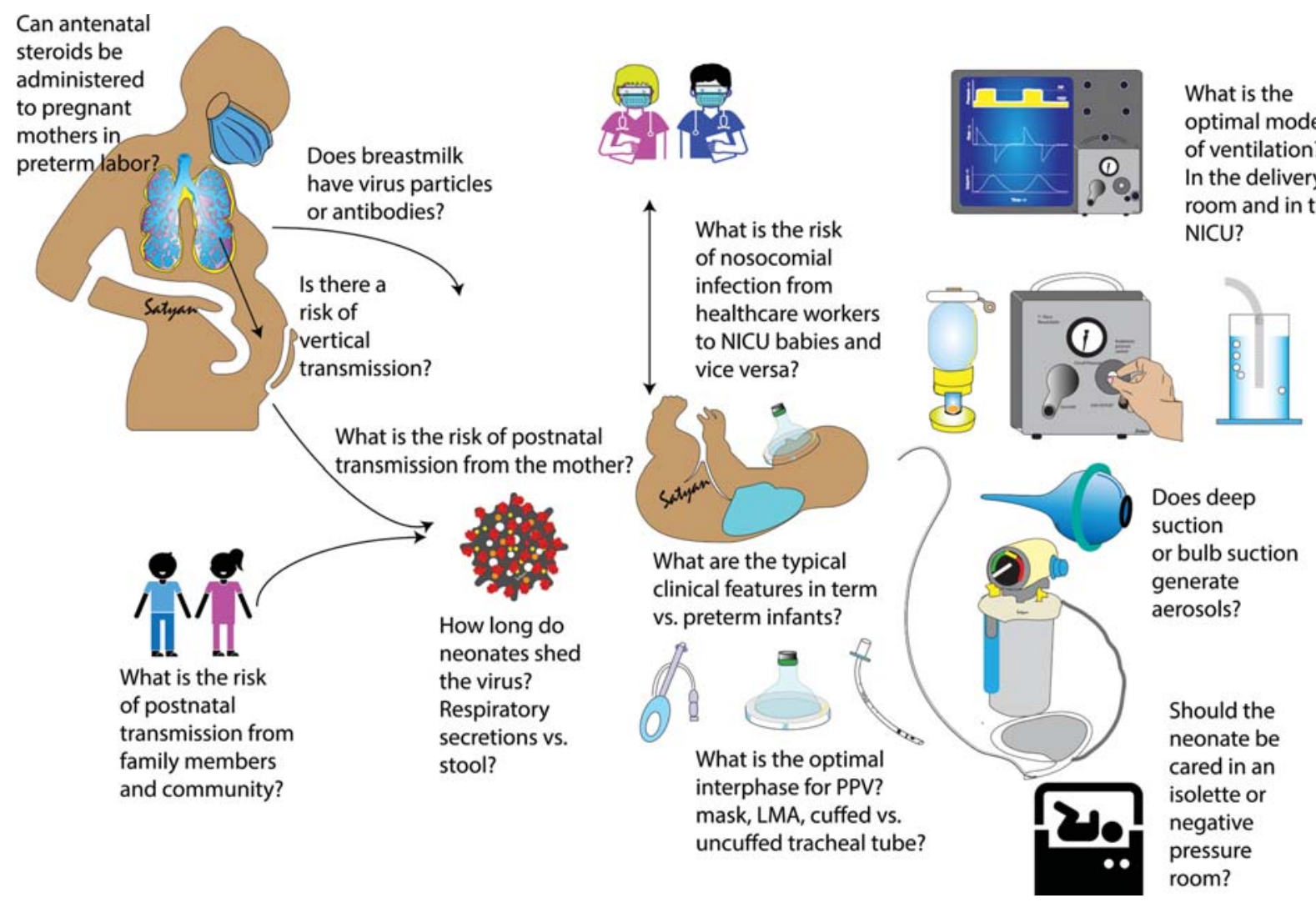

Fig. 1 Questions regarding transmission, clinical features, and optimal mode of respiratory support in neonates with suspected or confirmed COVID-19 infection. A balance between providing optimal respiratory care and minimizing exposure to healthcare workers is crucial. COVID-19, novel coronavirus disease 2019; LMA, laryngeal mask airway; NICU, neonatal intensive care unit; PPV, positive pressure ventilation. (Image courtesy: Satyan Lakshminrusimha). 
and cohort studies, describing the characteristics of infants born to mothers with positive SARS-CoV-2 infection and/or characteristics of infected neonates or infants less than 1 year of age were included. Information pertaining to clinical symptoms and adverse events following birth to a mother with positive SARS-CoV-2 or actual infection were gathered. Duplicate case reports were identified whenever possible and only presented once. Moreover, in infants born to mothers with positive SARS-CoV-2, results of investigational tests were described.

\section{Infants Born to Mothers with Positive SARS-CoV-2 Infection}

To date, the outcomes of 217 neonates ( 27 publications) born to mothers with positive SARS-CoV-2 have been reported (-Table 1). ${ }^{1-27}$ Of them, 210 (95\%) either tested negative for the virus (130/207) or were not tested given their unremarkable postnatal course (80/207). Of the seven remaining infants, three had equivocal test results and four had positive results. Of note, only 30 neonates (14\%) were born by spontaneous vaginal delivery, none of which tested positive for SARS-CoV-2 infection.
The vast majority of infants with negative test or not tested were asymptomatic after birth. However, a small proportion exhibited symptoms of common neonatal diseases. Only four infants required respiratory support after birth, $5,7,9,25$ of which one required mechanical ventilation (MV) on day 3 of life for frequent desaturations. ${ }^{17}$ An additional infant required MV on day 8 of life in the context of shock, multiorgan failure, and subsequent death (negative test at the time of clinical deterioration). ${ }^{25}$ Also, there was one reported case of stillbirth attributable to maternal acute respiratory distress syndrome (ARDS) and shock. ${ }^{17}$

Three infants had equivocal test results for SARS-CoV-2 despite having an otherwise uneventful postnatal course. ${ }^{22,26}$ All tested negative for SARS-CoV-2 using quantitative reverse transcriptase-polymerase chain reaction (RT-PCR) taken from the infants' nasopharyngeal swabs and serum as well as the maternal vaginal secretions and breask milk. However, they had elevated serum levels of immunoglobulin IgG and IgM antibodies for SARS-CoV-2 after birth. While the presence of IgM antibodies at high levels in the newborn raises the possibility of maternal-infant transmission, the negative RTPCR results are harder to explain. Moreover, caution is advised

\begin{tabular}{|c|c|c|c|c|c|c|}
\hline Study & $n$ & Region, country & GA range & Infant testing & Respiratory support & Neonatal illness \\
\hline \multicolumn{7}{|c|}{ Infants with negative testing, pending testing or not tested for SARS-CoV-2 } \\
\hline Breslin et al $^{1}$ & 18 & New York, USA & Not reported & Negative & Not specified & None \\
\hline Chen et $\mathrm{al}^{2}$ & 9 & Wuhan, China & $36-39^{4 / 7}$ & Negative $(6 / 6)$ & None & $\begin{array}{l}\text { Increased myocardial } \\
\text { enzymes }(1 / 9)\end{array}$ \\
\hline Chen et $\mathrm{al}^{4}$ & 5 & Wuhan, Chine & $38^{6 / 7}-40^{4 / 7}$ & Negative & None & None \\
\hline Chen et $\mathrm{al}^{5}$ & 4 & Wuhan, China & $37^{2 / 7}-39$ & Negative $(3 / 3)$ & CPAP for TTN $(1 / 4)$ & None \\
\hline Fan et $\mathrm{al}^{6}$ & 2 & Wuhan, China & $37 / 36^{5 / 7}$ & Negative & None & Mild neonatal pneumonia $(2 / 2)$ \\
\hline Gidlöf et $\mathrm{al}^{7}$ & 2 & Stockholm, Sweden & $36^{2 / 7}$ & Negative & CPAP for TTN $\left(1 / 2^{1} / 2\right)$ & None \\
\hline lqbal et $\mathrm{al}^{8}$ & 1 & Washington DC, USA & 39 & Negative & None & None \\
\hline ISN-SIN ${ }^{9}$ & 7 & Northern Italy & $34^{1 / 7}-40^{2 / 7}$ & Negative $(4 / 4)^{a}$ & $\begin{array}{l}\text { NIV for prematurity } \\
(1 / 7)\end{array}$ & None \\
\hline Khan et al ${ }^{10}$ & 17 & Wuhan, China & $35^{5 / 7}-41$ & Negative & Not specified & Neonatal pneumonia $(5 / 17)$ \\
\hline Lee et al $^{11}$ & 1 & Daegu, South Korea & $37^{6 / 7}$ & Negative & None & None \\
\hline Li et $\mathrm{al}^{12}$ & 17 & Wuhan, China & $33^{6 / 7}-40^{4 / 7}$ & Negative $(3 / 3)$ & None & Fetal distress (2/17) \\
\hline Li et al $^{13}$ & 1 & Zhejiang, China & 35 & Negative & None & None \\
\hline Liu et $\mathrm{al}^{14}$ & 11 & Wuhan, China & $34-38$ & Not done & None & None \\
\hline Liu et $\mathrm{al}^{15}$ & 16 & Shanghai, China & Not specified & Not done & None & None \\
\hline Liu et al $^{16}$ & 3 & Wuhan, China & $38^{4 / 7}-40$ & Negative & None & None \\
\hline Liu et $\mathrm{al}^{17}$ & 10 & Outside Wuhan & $32-38^{3 / 7}$ & Not specified & None & $\begin{array}{l}\text { Stillbirth for maternal ARDS } \\
\text { and shock }(1 / 10)\end{array}$ \\
\hline Wang et al ${ }^{18}$ & 1 & Suzhou, China & 30 & Negative & None & None \\
\hline Wu et al ${ }^{19}$ & 21 & Wuhan, China & $31^{5 / 7}-40$ & Negative (4/4) & None & None \\
\hline Zeng et $\mathrm{al}^{22}$ & 4 & Wuhan, China & Not specified & Negative & None & None \\
\hline Zeng et $\mathrm{al}^{23}$ & 30 & Wuhan, China & $\begin{array}{l}\text { Term }(27 / 30) \text {, } \\
\text { preterm }(3 / 30)\end{array}$ & Negative & None & $\begin{array}{l}\operatorname{RDS}(3 / 30), \text { cyanosis }(2 / 30) \text {, } \\
\text { asphyxia }(1 / 30)\end{array}$ \\
\hline Zhang et $\mathrm{al}^{24}$ & 10 & Wuhan, China & $35^{5 / 7}-41$ & Negative & Not reported & Bacterial pneumonia $(3 / 10)$ \\
\hline
\end{tabular}




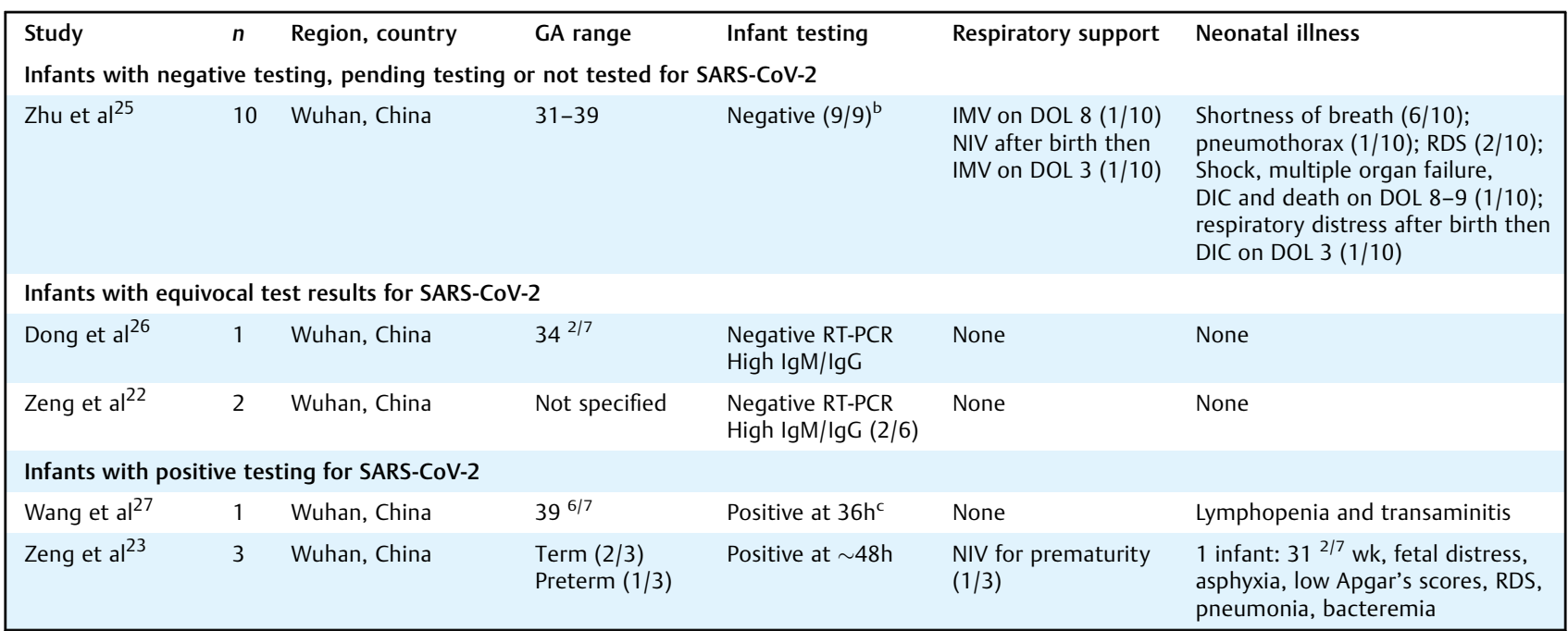

Abbreviations: ARDS, acute respiratory distress syndrome; CPAP, continuous positive airway pressure; DIC, disseminated intravascular coagulation; DOL, day of life; GA, gestational age (weeks); IMV, invasive mechanical ventilation; ISN-SIN, Italian Society of Neonatology report; NIV, noninvasive ventilation; PT, preterm; RDS, respiratory distress syndrome; SARS-CoV-2, severe acute respiratory syndrome-coronavirus-2; T, term; TTN, transient tachypnea of the newborn.

Notes: Testing for SARS-CoV-2 was performed using quantitative reverse transcriptase-polymerase chain reaction (RT-PCR) from various sources depending on the study:

Breslin et al, Chen Si et al, ${ }^{22}$ Chen Y et al, ${ }^{3}$ Li et al, ${ }^{12}$ Wang et al, ${ }^{27}$ Wu et al, ${ }^{19}$ Yu et al, Zhang et al, and Zhu et al ${ }^{2}$ : newborn nasopharyngeal swab. Chen et $\mathrm{al}^{2}$ : amniotic fluid, umbilical cord blood, breast milk and newborn nasopharyngeal swab.

Chen et $\mathrm{al}^{3}$ : placental tissues and newborn nasopharyngeal swab.

Dong et al: vaginal secretions, breast milk and newborn nasopharyngeal swab (the latter was tested five times).

Fan et al: amniotic fluid, umbilical cord blood, placental tissue, vaginal swab, breast milk and newborn nasopharyngeal swab.

Gidlöf et al: newborn nasopharyngeal swabs (at 34 hours and 4 days of life), vaginal secretions and breast milk.

lqbal et al: newborn nasopharyngeal swab done at $24 \mathrm{~h}$ of life was negative. Additionally, swabs from the maternal sites (amniotic fluid, vaginal side walls and rectum) and neonatal sites (nasopharynx, oropharynx, oral mucosa, skin surface, and rectum) were taken right after delivery but have not yet been processed due to high demand for testing in the laboratory.

ISN-SIN: newborn nasal or nasopharyngeal swabs.

Khan et al: umbilical cord blood and newborn nasopharyngeal swab.

Lee et al: placental tissue, amniotic fluid, umbilical cord blood and newborn nasopharyngeal swabs.

Li et al $^{13}$ : amniotic fluid, umbilical cord blood, placenta, breast milk, plasma serum, urine, feces and newborn oropharyngeal swab.

Liu et $a^{16}$ : umbilical cord blood (only patient 1), plasma serum, urine, feces and newborn oropharyngeal swab.

Wang et al: newborn nasopharyngeal swab done at 36 hours of life.

Wang et al: amniotic fluid, umbilical cord blood, placental tissue, gastric fluid and newborn nasopharyngeal swab.

Zambrano et al and Zeng et $\mathrm{al}^{22}$ : newborn plasma serum and nasopharyngeal swabs.

Zeng et $\mathrm{al}^{23}$ : newborn nasopharyngeal and anal swabs.

aThe remaining three infants had testing for SARS-CoV-2 but results were pending.

${ }^{b}$ The study by Yu et al. included seven infants born of pregnant women with COVID-19 infection. However, one of those infants was also reported in more detail as a separate case report by Wang et al. For that reason the sample size was decreased to 6 to avoid duplications.

${ }^{\mathrm{c}}$ After the result came back positive at $36 \mathrm{~h}$ of life, RT-PCR from the placental tissue, umbilical cord blood and breast milk were done and were all negative.

when using IgM assays to make the diagnosis of congenital infections since false positives are not uncommon. ${ }^{28}$

Only four infants born to mothers with positive SARS-CoV-2 infection had a positive test. ${ }^{23,27}$ However, given that all four infants were only diagnosed between 36 to 48 hours after birth (RT-PCR test from nasopharyngeal swabs), it is impossible to determine whether these infections were acquired in utero or postnatally. Moreover, although strict infectious control measures were reportedly implemented in those four infants, there was insufficient information regarding contact with the mother (or any other family members) and exposure to breastmilk. In the first case, a term infant born by normal delivery to a mother with confirmed COVID-19 had a benign postnatal course except for mild lymphopenia and mildly elevated liver enzymes. ${ }^{27}$ Testing for SARS-CoV-2 was positive at 36 hours of life but no respiratory support was needed throughout hospitalization. Importantly, RT-PCR tests performed on placental tissue, umbilical cord blood, and breast milk were all negative. In the second and third cases, ${ }^{23}$ two term infants with unremarkable delivery developed fever and lethargy on the second day of life and their RT-PCR was positive at approximately 48 hours after birth. Both infants rapidly improved and did not require respiratory support. In the last case, ${ }^{23}$ a preterm infant ( $31^{2 / 7}$ weeks' gestation) born by caesarean section for fetal distress had low Apgar's scores, developed respiratory distress syndrome requiring noninvasive support, and later developed 
bacteremia and coagulopathy. Testing for SARS-CoV-2 also was positive at approximately 48 hours after birth.

All in all, infants born to mothers with positive SARS-CoV2 infection generally have favorable outcomes, with no convincing case of vertical transmission, at least when delivery route was caesarean section. In the few cases where infants had a positive or equivocal test, postnatal course was generally uneventful.

\section{Neonates and Infants Less than 1 Year Old with Positive SARS-CoV-2 Infection}

Epidemiological data from the countries with the largest number of COVID-19 cases (China, Italy, and the United States of America) have demonstrated that children represent a minority of the overall cases ( - Table 2 ). In a cohort from China of 72,314 individuals with SARS-CoV-2 infection, only $1 \%$ of reported cases were children with $<10$ years of age. ${ }^{29}$ Similarly, in a cohort of 22,512 individuals with COVID-19 from Italy, $1.2 \%$ of cases were children between the age of 0 and 18 years. ${ }^{30}$ More recently, a report from the Centers for Disease Control and prevention in the United States found that out of 149,760 confirmed cases of COVID-19,2,572 (1.7\%) were children with $<18$ years, of which 398 ( $0.3 \%$ of all cases) were $<1$ year old. ${ }^{31}$ While the number of pediatric COVID-19 cases appears to be low, the exact incidence and associated morbidities/mortality of SARS-CoV-2 infection in neonates and young infants are not clear. We identified 18 publications that described the clinical manifestations and outcomes from a total of 856 neonates and

\begin{tabular}{|c|c|c|c|c|c|}
\hline Study & $n$ & Region, country & $\begin{array}{l}\text { Age } \\
\text { range }\end{array}$ & Need for respiratory support & Symptoms/outcomes \\
\hline Cai et $\mathrm{al}^{32}$ & 2 & $\begin{array}{l}\text { Shanghai and } \\
\text { Haikou, China }\end{array}$ & $\begin{array}{l}3 \text { and } \\
7 \text { mo }\end{array}$ & None & Fever and mild URTI symptoms \\
\hline $\begin{array}{l}\text { Canarutto } \\
\text { et } \mathrm{al}^{33}\end{array}$ & 1 & Milan, Italy & $32 \mathrm{~d}$ & None & Fever and mild URTI symptoms \\
\hline $\mathrm{CDC}^{31}$ & 398 & United States & $0-1$ y & Not specified & $\begin{array}{l}59 \text { out of } 95 \text { infants with known } \\
\text { hospitalization status were } \\
\text { hospitalized, of which } 5 \text { required } \\
\text { intensive care }\end{array}$ \\
\hline Cui et $\mathrm{al}^{34}$ & 1 & Guiyang, China & $55 d$ & Oxygen therapy & $\begin{array}{l}\text { Pneumonia, increased } \\
\text { myocardial/liver enzymes }\end{array}$ \\
\hline Dong et $\mathrm{al}^{35}$ & 379 & Mainland China & $0-1$ y & Not specified & $\begin{array}{l}7(2 \%) \text { asymptomatic } \\
205(54 \%) \text { mild } \\
127(34 \%) \text { moderate } \\
33(9 \%) \text { severe } \\
7(2 \%) \text { critical }\end{array}$ \\
\hline ISN-SIN ${ }^{9}$ & 5 & Northern Italy & $2-44 d$ & Oxygen therapy $(1 / 5)$ & $\begin{array}{l}\text { Fever and/or mild URTI } \\
\text { symptoms conjunctivitis }\end{array}$ \\
\hline Kam et $\mathrm{al}^{36}$ & 1 & $\begin{array}{l}\text { Singapore, } \\
\text { Singapore }\end{array}$ & $6 \mathrm{mo}$ & None & Fever \\
\hline Kamali et al ${ }^{37}$ & 1 & Zanjan, Iran & $15 d$ & Oxygen therapy & Fever, mild tachypnea \\
\hline Le et $\mathrm{al}^{38}$ & 1 & Hanoi, Vietnam & $3 \mathrm{mo}$ & None & Mild URTI symptoms \\
\hline Li et $\mathrm{al}^{39}$ & 1 & Zhuhai, China & $10 \mathrm{mo}$ & No & Asymptomatic \\
\hline Liu et $\mathrm{al}^{15}$ & 2 & Shanghai, China & $\begin{array}{l}2 \text { and } \\
11 \mathrm{mo}\end{array}$ & Not specified & $\begin{array}{l}\text { Both had mild pneumonia, } \\
\text { one infant also had pleural } \\
\text { effusion and was RSV positive }\end{array}$ \\
\hline Lu et $\mathrm{al}^{40}$ & 31 & Wuhan, China & $0-1$ y & $\begin{array}{l}1 \text { infant required IMV due to } \\
\text { intussusception and multiorgan } \\
\text { failure ( } 4 \text { weeks after admission) }\end{array}$ & $\begin{array}{l}0 \text { asymptomatic } \\
6(19 \%) \text { URTI symptoms } \\
25(81 \%) \text { pneumonia } \\
1(3 \%) \text { death }\end{array}$ \\
\hline Qiu et $\mathrm{al}^{41}$ & 10 & Zhejiang, China & $0-5 y$ & Oxygen therapy $(1 / 10)$ & $\begin{array}{l}4(40 \%) \text { asymptomatic/mild } \\
6(60 \%) \text { moderate }\end{array}$ \\
\hline Su et $\mathrm{al}^{42}$ & 2 & Jinan, China & $11 \mathrm{mo}$ & None & Mild pneumonia $(1 / 2)$ \\
\hline Wei et $\mathrm{al}^{43}$ & 9 & Mainland China & $28 d-1 y$ & None & Fever or mild URTI symptoms \\
\hline Xia et al ${ }^{44}$ & 9 & Wuhan, China & $0-1$ y & Not specified & $\begin{array}{l}\text { Neonates: asymptomatic }(3 / 3) \\
\text { Others: asymptomatic } \\
\text { or mild pneumonia }\end{array}$ \\
\hline Zeng et al ${ }^{45}$ & 1 & Wuhan, China & $17 d$ & None & $\begin{array}{l}\text { Mild symptoms } \\
\text { (fever, vomiting, diarrhea) }\end{array}$ \\
\hline Zhang et al ${ }^{46}$ & 1 & Haikou, China & $3 \mathrm{mo}$ & None & Mild URTI symptoms \\
\hline
\end{tabular}

Abbreviations: CDC, Center for Disease Control and Prevention; COVID-19, novel coronavirus disease 2019; IMV, invasive mechanical ventilation; ISNSIN, Italian Society of Neonatology; RSV, respiratory syncytial virus; URTI, upper respiratory tract infection. 
infants under 1 year with SARS-CoV-2 infection..$^{9,15,31-46}$ All but three were case reports or case series that included fewer than 10 infants $<1$ year. Of the 48 infants described in these reports, all were either asymptomatic, had mild fever and upper respiratory tract infection symptoms, or mild pneumonia. Only four infants required oxygen supplementation, and none needed additional respiratory support or intensive care. Furthermore, only nine infants were described to have acquired the infection during the neonatal period, ${ }^{9,37,44,45}$ and all were either asymptomatic carriers or had mild respiratory symptoms. In the third largest publication, Lu et al described the evolution of 31 infants between the ages of 0 to 1 year with SARS-CoV-2 infection. ${ }^{40}$ The majority (80\%) presented with pneumonia but did not require any respiratory support. Of note, one infant died from multiorgan failure due to an intussusception. In the most recent $\mathrm{CDC}$ report, among 95 infants $<1$ year with known hospitalization status, 59(62\%) required hospitalization, but only 5 were in intensive care. ${ }^{31}$ In the largest pediatric cohort study to date, Dong et al described the clinical characteristics and outcomes of 2,143 children from China with suspected or confirmed SARS-CoV-2 infection, among which $379(18 \%)$ were infants under 1 year. ${ }^{35}$ In the latter group, 33 developed severe pneumonia with hypoxemia (requiring respiratory support) and 7 were in critical condition (developed ARDS and shock) but eventually recovered. While this study suggests that close to $10 \%$ of infants with ages 0 - to 1 -year age develop severe or critical illness, it is important to note that only 86/379 infants actually had a confirmed diagnosis of SARSCoV-2 infection (by RT-PCR or through genomic sequencing). The other 293 infants were suspected cases based on fulfilling clinical, laboratory, or radiological criteria. Considering that the proportion of severe/critical presentations in the study were significantly higher in the suspected, compared with the confirmed COVID-19 cases, this raises the possibility that many of the suspected cases may have been caused by viral pathogens other than SARS-CoV-2.

Thus, although the majority of neonates and infants under 1 year with SARS-CoV-2 infection appear to have generally favorable outcomes, the risk of severe or critical illness exists. Intriguingly, the reason why infants display a milder spectrum of disease compared with adults remains unclear and is the subject of ongoing investigations. ${ }^{47,48}$

\section{Terminology}

The provision of respiratory care remains an integral component of the management of neonates, whether during the transition period after birth or during NICU hospitalization. Respiratory support practices should follow an evidencebased approach for treating patients and protecting HCW from the virus. An important first step is to define neonatal ARDS in the context of suspected or confirmed COVID-19 infection. Is there a specific clinical feature attributable to COVID-19 when dealing with neonatal respiratory distress? In 2017, an international multicenter collaborative produced a consensus definition for neonatal ARDS. ${ }^{49}$ This definition might help to standardize the processes for identifying suspected cases of SARS-CoV-2 infection and classifying them according to their illness severity. Moreover, as the number of deaths in neonates positive for SARS-CoV-2 may become increasingly reported, this definition will help to differentiate between deaths attributable to pregnancy complications (e.g., prematurity and asphyxia) and deaths attributable to the infection itself.

In the next section, a practical approach and mostly physiology-based approach to the respiratory care of neonates with suspected or confirmed SARS-CoV-2 infection is provided and summarized in -Table 3 . Of note, for all aspects of respiratory care described below, HCW should use adequate full personal protective equipment (PPE) including a long-sleeved gown, single-use gloves, eye protection, and a N95 mask or the equivalent as the minimum level of respiratory protection.

\section{Management}

Specific guidance for respiratory management of COVID-19 in neonates is not yet available as positive infants who needed some support were either premature or affected by comorbidities. Therefore, the true picture of SARS-CoV-2 in neonates will likely arise from further studies and larger case series over the next weeks. Nevertheless, in the meantime, NICUs have to establish guidelines or protocols for respiratory management and necessary precautions.

\section{Delivery Room Management and Transport from the Delivery Room to the NICU}

As the likelihood of vertical transmission is very low, neonatal resuscitation should be performed according to the Neonatal Resuscitation Program 7 th edition, ${ }^{50}$ with slight modifications (outlined below) for some respiratory care practices. To minimize HCW exposure, the least number of personnel should enter the delivery room (DR) with standby staff outside the room. Following initial stabilization, the infant should be placed in an incubator and transported via a short, preestablished pathway to the NICU (-Fig. 2).

\section{Respiratory Management in the NICU}

A major concern when applying any type of respiratory support to patients with suspected or confirmed viral infection is the generation of aerosol-containing particles that can spread the disease. ${ }^{51}$ The theoretical risk of aerosol generation and dispersion stems from various factors, including the proximity to the patient's upper airway and risk of dispersion through interface leaks or respiratory circuits. In 2014, the WHO systematically reviewed and graded the evidence for using different protective measures during AGPs. All included studies were of very low quality, and none included neonates. ${ }^{52}$ Therefore, in the absence of scientific evidence, a physiology-driven approach in infants with suspected or confirmed SARS-CoV-2 infection is outlined here.

\section{Manual Ventilation}

The risk of viral transmission with manual ventilation has only been evaluated in a few adult studies. In a systematic review, manual ventilation (before or after intubation) was not 
Table 3 Practical approach to neonates with suspected or conformed COVID-19

\begin{tabular}{|c|c|}
\hline $\begin{array}{l}\text { Bag and mask/ } \\
\text { T-piece and mask } \\
\text { ventilation }\end{array}$ & $\begin{array}{l}\text { Delivery room and NICU: should continue to be used as recommended by the NRP, with all protective measures } \\
\text { in place for suspected or confirmed cases. } \\
\text { A small viral/bacterial filter should be placed in between the T-piece resuscitator or anesthesia bag and the mask } \\
\text { or in the expiratory limb (before the PEEP valve) of a self-inflating bag. Normally, the filter should be replaced } \\
\text { every } 8-12 \text { hours. } \\
\text { Note: when placed between the T-piece or anesthesia bag and mask, the filter adds significant dead space. For } \\
\text { that reason, the smallest available filter should be used and prolonged ventilation using this apparatus should be } \\
\text { avoided. } \\
\text { Since no positive COVID-19 cases were detected in infants }<1,000 \mathrm{~g} \text { it may be reasonable to not use filters while } \\
\text { applying bag and mask ventilation to these infants to avoid possible iatrogenic hypercapnia with subsequent } \\
\text { intraventricular hemorrhage. }\end{array}$ \\
\hline $\begin{array}{l}\text { Suction } \\
\text { (oropharyngeal } \\
\text { area and ETT) }\end{array}$ & $\begin{array}{l}\text { Non-intubated infant: continuous suctioning reduces aerosol spread better than several episodes of inter- } \\
\text { mittent suctioning. In this respect, open airway toileting should be performed with continuous suctioning. } \\
\text { Mechanically ventilated infants: a closed-circuit suction should be always inline and used for endotracheal } \\
\text { suctioning. }\end{array}$ \\
\hline $\begin{array}{l}\text { Continuous } \\
\text { positive } \\
\text { airway pressure }\end{array}$ & $\begin{array}{l}\text { Delivery room and NICU: should continue to be used as recommended by the NRP with all protective measures } \\
\text { in place for suspected or confirmed COVID- } 19 \text { cases. } \\
\text { A viral/bacterial filter should be placed in the expiratory limb (before the water reservoir for the bubble system) } \\
\text { or before the ventilator exhalation valve. Normally, the filter should be replaced every } 8-12 \text { hours. }\end{array}$ \\
\hline $\begin{array}{l}\text { Noninvasive } \\
\text { positive pressure } \\
\text { ventilation }\end{array}$ & $\begin{array}{l}\text { Delivery room and NICU: is acceptable as long as all protective measures are in place for suspected or confirmed } \\
\text { COVID-19 cases. } \\
\text { A viral/bacterial filter should be placed in the expiratory limb of the system. } \\
\text { Note: if those measures are not available or reliable, then intubation and mechanical ventilation is a reasonable } \\
\text { option. }\end{array}$ \\
\hline $\begin{array}{l}\text { Endotracheal } \\
\text { intubation }\end{array}$ & $\begin{array}{l}\text { Delivery room and NICU: is the procedure associated with higher risk of contamination. Therefore, the operator } \\
\text { should have experience and be properly protected. If possible, use a video laryngoscopy system to maintain } \\
\text { some distance from the patient airway. }\end{array}$ \\
\hline $\begin{array}{l}\text { Mechanical } \\
\text { ventilation }\end{array}$ & $\begin{array}{l}\text { NICU: should continue to be used in the NICU as per unit protocols as long as all protective measures are in place } \\
\text { for suspected or confirmed COVID- } 19 \text { cases. There are no data to recommend a specific mode. } \\
\text { A viral/bacterial filter should be placed on the expiratory limb before the ventilator exhalation valve (not feasible } \\
\text { with high-frequency oscillatory ventilation). Normally, the filter should be replaced every } 8-12 \text { hours. A closed } \\
\text { ETT suction apparatus should be used. }\end{array}$ \\
\hline
\end{tabular}

Abbreviations: COVID-19, novel coronavirus disease 2019; ETT, endotracheal tube; NICU, neonatal intensive care unit; NRP, neonatal resuscitation; PEEP, positive end expiratory pressure.

independently associated with increased risk of viral transmis$\operatorname{sion}^{53}$ and the odds of acquiring a viral infection were three times higher during endotracheal intubation compared with bagging. ${ }^{54}$ In a series of physiological experiments, Chan et al programmed an adult simulator to mimic varying severities of lung injury. ${ }^{55,56}$ When a tidal volume (VT) of $300 \mathrm{~mL}$ was applied, air dispersion reached up to 0.3 to $0.35 \mathrm{~m}$. Presumably, lower VT would produce less air dispersion. Indeed, in another experiment using noninvasive ventilation, a five-fold decrease in VT was associated with a $30 \%$ reduction in air dispersion. ${ }^{57}$ Thus, using this nonlinear relationship, mask and bag ventilation of a neonate weighing $3 \mathrm{~kg}$ using VT between 15 to $18 \mathrm{~mL}$ (16-20 times lower than adults) would generate a small air dispersion of approximately 1.5 to $1.8 \mathrm{~cm}$ ( - Fig. 3). Technical skills to minimize exhaled air dispersion is also paramount since inexperienced HCW can increase the spread by $40 \%{ }^{55}$ Thus, in neonatal respiratory care, avoidance of manual ventilation solely for the purpose of preventing air dispersion appears unnecessary.

To further protect HCW during manual ventilation, several NICUs have also embraced the use of bacterial/viral filters. While the filter is effective in reducing viral dispersion, ${ }^{55,56}$ there are important considerations to its use. For example, addition of a filter can increase the bulk of the device and reduce efficiency by increasing mask leaks. Furthermore, caution is advised when improvising equipment because interposing an adult-sized filter would add approximately $40 \mathrm{~mL}$ of dead space, which would result in completely ineffective gas exchange. Even smaller filters add approximately $10 \mathrm{~mL}$ of dead space, which could be detrimental to a small preterm infant if kept in place for an extended period (-Fig. 3). Since no positive COVID-19 cases were detected in infants $<1,000 \mathrm{~g}$, it may be reasonable to not use filters while applying bag and mask ventilation to these infants to avoid possible iatrogenic hypercapnia with subsequent intraventricular hemorrhage.

\section{Suction (Mouth and Nasopharynx)}

Pooled estimates from a systematic review have demonstrated that activities such as suctioning and collection of sputum samples were not associated with increased risks of infection transmission. ${ }^{53}$ However, some evidence from adult studies suggests that in nonintubated patients, continuous suctioning may be more effective at reducing aerosol dispersion compared with intermittent suctioning. ${ }^{55}$

\section{Noninvasive Respiratory Support}

CPAP and nasal intermittent positive pressure ventilation (NIPPV) may play a supportive role in infants with viral pneumonia and early ARDS. Considering that some viral infections can convert from droplets to airborne during respiratory therapy, it is possible that CPAP and NIPPV 


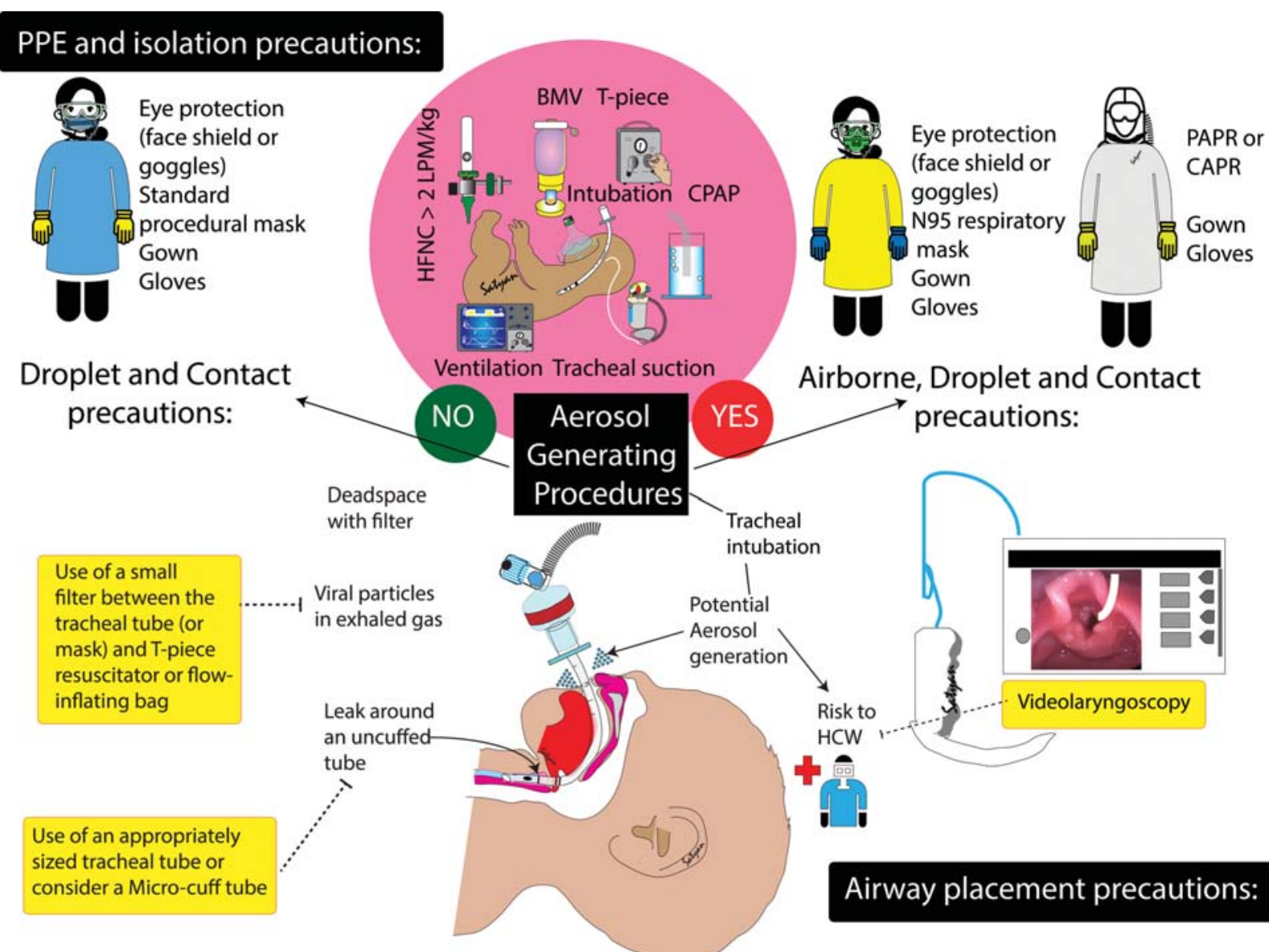

Fig. 2 Strategies to minimize risk to neonatal health care workers. Personal protective equipment (PPE) for droplet and contact precautions (recommended for nonaerosol generating situations) and airborne precautions (for aerosol generating procedures). Airborne precautions can utilize $\mathrm{N} 95$ masks with eye protection or powered air-purifying respirators (PAPR) or controlled air-purifying respirators (CAPR). Tracheal intubation carries a high risk of aerosolization. The use of a viral filter, appropriately sized tracheal tube (or a micro-cuff tube) to minimize air leak, and video laryngoscopy are some strategies that can reduce risk to health care workers (HCW). (Image courtesy: Satyan Lakshminrusimha)

may disperse infected aerosols and contribute to nosocomial transmission. However, during the SARS outbreak, many adult patients were safely and effectively treated with both therapies in hospitals with good infection control measures (proper room air exchange rate and adequate PPE). ${ }^{54,57,58}$ Simonds et al evaluated air dispersion during NIPPV and found generation of droplets of $>10 \mu \mathrm{m}$ in size, ${ }^{59}$ suggesting that most droplets deposit on local surfaces within a short distance. While this reduces the risk of viral acquisition by inhalation, these surfaces may serve as a source of infection in the absence of strict precautions. In another experiment in adults, exposure to exhaled air occurred within a $1-\mathrm{m}$ region $(0.3-0.85 \mathrm{~m})$ when using three different types of interfaces and VT of $300 \mathrm{~mL}$ (16-20 times the VT of a $3-\mathrm{kg}$ infant). ${ }^{60}$

Therefore, CPAP and NIPPV appear to be safe in neonates if used in adequately ventilated room, with proper protection measures, careful fitting of the interface, and addition of hydrophobic filter between the interface and water reservoir (bubble CPAP) or exhalation port of ventilators (CPAP or NIPPV). However, since the filter may increase expiratory resistance, spot checks of the pressure (measured at the expiratory limb) can ensure safe application.
High-flow nasal cannula (HFNC) has gained popularity in neonatology as an alternative to CPAP. Limited available data from adults suggest that there is possibly a substantial dispersion of exhaled air with HFNC that increases with liter flow and VT. ${ }^{61}$ Extrapolating to neonates would suggest very limited distance of dispersion but no specific data are available.

\section{Endotracheal Intubation}

From the available evidence, endotracheal intubation has consistently been associated with the greatest risk of viral transmission due to the unavoidable short distance between the operator face and patient airways with virus acquisition coming from simple breathing of the patient. ${ }^{53}$ Recently, an influenza study confirmed that only bronchoscopy and intubation were significant AGPs. ${ }^{54}$ Such information is not available in neonates, nor are there any data regarding surfactant administration either with traditional endotracheal tube (ET) instillation or using less invasive techniques as AGPs. Thus, because of the potential risk of transmission, endotracheal intubation should be performed by skilled providers using full PPE. An appropriately sized ET should be used to avoid excessive leak. 


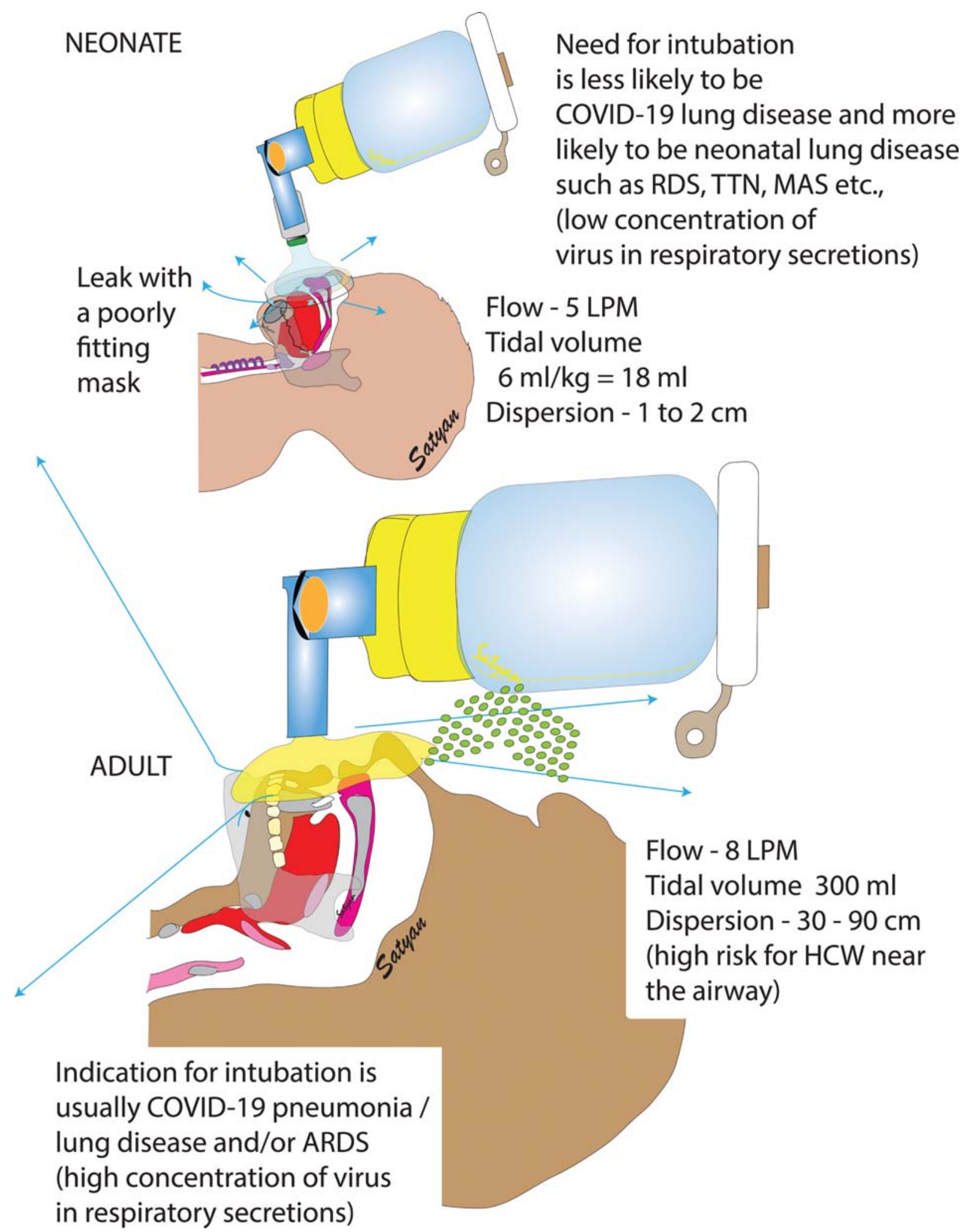

Fig. 3 Differences between neonatal and adult aerosol dispersion during bag-mask ventilation. The area of dispersion is much lower in neonates due to lower airflow and smaller tidal volumes. However, a poorly fitting mask can enhance air-leak. ARDS, acute respiratory distress syndrome; COVID-19, novel coronavirus disease 2019; HCW, health care workers; LPM, liters per minute; MAS, Meconium aspiration syndrome; RDS, respiratory distress syndrome; TTN, transient tachypnea of the newborn. (Image courtesy: Satyan Lakshminrusimha) 


\section{Mechanical Ventilation}

Infants with suspected or confirmed SARS-CoV-2 infection requiring MV should be placed under isolation precautions. Neonates are usually intubated with uncuffed ET due to risks of upper airway injury. This may lead to leaks around the tube and create aerosol dispersion. However, due to the small VT used, the magnitude of dispersion is likely minor (-Fig. 3). Also, a closed ET suction circuit should be used, and a hydrophobic filter placed at the exhalation port (never between the circuit adapter and ET). There are no clear data to support any specific mode of ventilation to treat viral pneumonia/ARDS in neonates or decrease aerosol dispersion. High-frequency ventilation seems to be safe as investigated in one adult study. ${ }^{54}$ However, it should be noted that while with conventional and highfrequency jet ventilation exhaled gases exit via the expiratory limb and therefore can be captured by a filter, during high-frequency oscillatory ventilation with the SensorMedics $3100 \mathrm{~A}$ or $\mathrm{B}$, the exhaled gases are exhausted directly into the ambient air.

\section{Conclusion}

After having witnessed nearly 2 million cases of COVID-19 worldwide, the proportion of neonates with the disease is extremely low. Moreover, neonatal COVID-19 appears to be acquired postnatally and associated with favorable respiratory outcomes. For those reasons, provision of respiratory care in newborn infants should continue in accordance with current standards and major practice changes should be avoided to minimize harm. However, to protect HCW from suspected or confirmed cases of neonatal SARS-CoV-2 infection, it is critical to consistently implement safe respiratory practices including proper patient isolation, optimal PPE, and the use of viral filters to the expiratory limbs of any respiratory device. Lastly, information is changing rapidly, and clinicians should watch frequently for updates as the state of knowledge evolves.

\section{Authors' Contributions}

W.S. and G.M.S. conceptualized and designed the review, drafted the initial manuscript, and reviewed and revised the manuscript. P.M. and M.K. reviewed the extracted data and analyses of the cases and reviewed and revised the final manuscript including all tables and figures. S.L. conceptualized and designed all figures, participated on several drafts of the manuscript, and reviewed and revised the final manuscript, including all tables. All authors critically reviewed the manuscript for important intellectual content. All authors approved the final manuscript as submitted and agree to be accountable for all aspects of the work.

\section{Funding}

None.

\section{Conflict of Interest}

None declared.

\section{References}

1 Breslin N, Baptiste C, Gyamfi-Bannerman C, et al. COVID-19 infection among asymptomatic and symptomatic pregnant women: two weeks of confirmed presentations to an affiliated pair of New York City hospitals. Am J Obstet Gynecol MFM 2020 (e-pub ahead of print). doi: 10.1016/j.ajogmf.2020.100118

2 Chen H, Guo J, Wang C, et al. Clinical characteristics and intrauterine vertical transmission potential of COVID-19 infection in nine pregnant women: a retrospective review of medical records. Lancet 2020;395(10226):809-815

3 Chen S, Huang B, Luo DJ, et al. [Pregnant women with new coronavirus infection: a clinical characteristics and placental pathological analysis of three cases] (in Chinese). Zhonghua Bing Li Xue Za Zhi 2020;49(00):E005

4 Chen S, Liao E, Cao D, Gao Y, Sun G, Shao Y. Clinical analysis of pregnant women with 2019 novel coronavirus pneumonia. J Med Virol 2020 (e-pub ahead of print). Doi: 10.1002/jmv.25789

5 Chen Y, Peng H, Wang L, et al. Infants born to mothers with a new coronavirus (COVID-19). Front Pediatr 2020;8(104):104

6 Fan C, Lei D, Fang C, et al. Perinatal transmission of COVID-19 associated SARS-CoV-2: should we worry? Clin Infect Dis 2020: ciaa226 (e-pub ahead of print). Doi: 10.1093/cid/ciaa226

7 Gidlöf S, Savchenko J, Brune T, Josefsson H. COVID-19 in pregnancy with comorbidities: More liberal testing strategy is needed. Acta Obstet Gynecol Scand 2020 (e-pub ahead of print). Doi: 10.1111/aogs.13862

8 Iqbal SN, Overcash R, Mokhtari N, et al. An uncomplicated delivery in a patient with COVID-19 in the United States. N Engl J Med 2020;382(16):e34 (e-pub ahead of print). Doi: 10.1056/ NEJMc2007605

9 SINInforma 2020: [Management of the newborn with suspected or confirmed SARS-CoV-2 infection]. Available at: https://www. sin-neonatologia.it/pdf/SIN_INFORMA_n78_speciale_covid19. pdf. Accessed April 6, 2020

10 Khan S, Jun L, Nawsherwan, et al. Association of COVID-19 infection with pregnancy outcomes in healthcare workers and general women. Clin Microbiol Infect 2020;S1198-743X(20) 30180-4 (e-pub ahead of print). Doi: 10.1016/j.cmi.2020.03.034

11 Lee DH, Lee J, Kim E, Woo K, Park HY, An J. Emergency caesarean section on severe acute respiratory syndrome coronavirus 2 (SARS- CoV-2) confirmed patient. Korean J Anesthesiol 2020 (epub ahead of print). Doi: 10.4097/kja.20116

12 Li N, Han L, Peng M, et al. Maternal and neonatal outcomes of pregnant women with COVID-19 pneumonia: a case-control study. Clin Infect Dis 2020:ciaa352 (e-pub ahead of print). Doi: $10.1093 / \mathrm{cid} / \mathrm{ciaa} 352$

13 Li Y, Zhao R, Zheng S, et al. Lack of vertical transmission of severe acute respiratory syndrome coronavirus 2, China. Emerg Infect Dis 2020;26(06):1335-1336

14 Liu D, Li L, Wu X, et al. Pregnancy and perinatal outcomes of women with coronavirus disease (COVID-19) pneumonia: a preliminary analysis. Am J Roentgenol 2020:1-6 (e-pub ahead of print). Doi: 10.2214/AJR.20.23072

15 Liu H, Liu F, Li J, Zhang T, Wang D, Lan W. Clinical and CT imaging features of the COVID-19 pneumonia: Focus on pregnant women and children. J Infect 2020;80(05):e7-e13

16 Liu W, Wang Q, Zhang Q et al. Coronavirus disease 2019 (COVID-19) during pregnancy: a case series. Preprints 2020: 2020020373

17 Liu Y, Chen H, Tang K, Guo Y. Clinical manifestations and outcome of SARS-CoV-2 infection during pregnancy. J Infect 2020;S01634453(20)30109-2 (e-pub ahead of print). Doi: 10.1016/j.jinf. 2020.02.028

18 Wang X, Zhou Z, Zhang J, Zhu F, Tang Y, Shen X. A case of 2019 Novel Coronavirus in a pregnant woman with preterm delivery. Clin Infect Dis 2020:ciaa200 (e-pub ahead of print). Doi: 10.1093/ $\mathrm{cid} /$ ciaa200 
19 Wu X, Sun R, Chen J, Xie Y, Zhang S, Wang X. Radiological findings and clinical characteristics of pregnant women with COVID-19 pneumonia. Int J Gynaecol Obstet 2020 (e-pub ahead of print). Doi: 10.1002/ijgo.13165

20 Yu N, Li W, Kang Q, et al. Clinical features and obstetric and neonatal outcomes of pregnant patients with COVID-19 in Wuhan, China: a retrospective, single-centre, descriptive study Lancet Infect Dis 2020;S1473-3099(20)30176-6 (e-pub ahead of print). Doi: 10.1016/S1473-3099(20)30176-6

21 Zambrano LI, Fuentes-Barahona IC, Bejarano-Torres DA, et al. A pregnant woman with COVID-19 in Central America. Travel Med Infect Dis 2020:101639 (e-pub ahead of print). Doi:10.1016/j. tmaid.2020.101639

22 Zeng H, Xu C, Fan J, et al. Antibodies in infants born to mothers with COVID-19 pneumonia. JAMA 2020 (e-pub ahead of print) Doi: $10.1001 /$ jama.2020.4861

23 Zeng L, Xia S, Yuan W, et al. Neonatal early-onset infection with SARS-CoV-2 in 33 neonates born to mothers with COVID-19 in Wuhan, China. JAMA Pediatr 2020 (e-pub ahead of print). Doi: 10.1001/jamapediatrics.2020.0878

24 Zhang L, Jiang Y, Wei M, et al. [Analysis of the pregnancy outcomes in pregnant women with COVID-19 in Hubei Province] (in Chinese). Zhonghua Fu Chan Ke Za Zhi 2020;55(00):E009

25 Zhu H, Wang L, Fang C, et al. Clinical analysis of 10 neonates born to mothers with 2019-nCoV pneumonia. Transl Pediatr 2020;9(01): 51-60

26 Dong L, Tian J, He S, et al. Possible vertical transmission of SARSCoV-2 from an infected mother to her newborn. JAMA 2020 (epub ahead of print). Doi: 10.1001/jama.2020.4621

27 Wang S, Guo L, Chen L, et al. A case report of neonatal COVID-19 infection in China. Clin Infect Dis 2020:ciaa225 (e-pub ahead of print). Doi: 10.1093/cid/ciaa225

28 Kimberlin DW, Stagno S. Can SARS-CoV-2 infection be acquired in utero? More definite evidence is needed. JAMA 2020 (e-pub ahead of print). Doi: 10.1001/jama.2020.4868

$29 \mathrm{Wu}$ Z, McGoogan JM. Characteristics of and important lessons from the Coronavirus Disease 2019 (COVID-19) outbreak in China: summary of a report of 72314 cases from the Chinese Center for Disease Control and Prevention. JAMA 2020 (e-pub ahead of print). Doi: 10.1001/jama.2020.2648

30 Livingston E, Bucher K. Coronavirus disease 2019 (COVID-19) in Italy. JAMA 2020 (e-pub ahead of print). Doi: 10.1001/jama. 2020.4344

31 CDC COVID-19 Response Team. Coronavirus disease in children United States, February 12-April 2, 2020. MMWR Morb Mortal Wkly Rep 2020;69(14):422-426

32 Cai J, Xu J, Lin D, et al. A case series of children with 2019 novel coronavirus infection: clinical and epidemiological features. Clin Infect Dis 2020:ciaa198 (e-pub ahead of print). Doi: 10.1093/cid/ ciaa198

33 Canarutto D, Priolo A, Russo G, Pitea M, Vigone MC, Barera G. COVID-19 infection in a paucisymptomatic infant: Raising the index of suspicion in epidemic settings. Pediatr Pulmonol 2020 (e-pub ahead of print). Doi: 10.1002/ppul.24754

34 Cui Y, Tian M, Huang D, et al. A 55-day-old female infant infected with COVID 19: presenting with pneumonia, liver injury, and heart damage. J Infect Dis 2020:jiaa113 (e-pub ahead of print). Doi: 10.1093/infdis/jiaa113

35 Dong Y, Mo X, Hu Y, et al. Epidemiological characteristics of 2143 pediatric patients with 2019 coronavirus disease in China. Pediatrics 2020 (e-pub ahead of print). Doi: 10.1542/peds.2020-0702

36 Kam KQ Yung CF, Cui L, et al. A well infant with Coronavirus Disease 2019 (COVID-19) with high viral load. Clin Infect Dis 2020:ciaa201 (e-pub ahead of print). Doi: 10.1093/cid/ciaa201

37 Aghdam MK, Jafari N, Eftekhari K. Novel coronavirus in a 15-dayold neonate with clinical signs of sepsis, a case report. Infect Dis (Lond) 2020: 427-429 (e-pub ahead of print). Doi: 10.1080/ 23744235.2020.1747634
38 Le HT, Nguyen LV, Tran DM, et al. The first infant case of COVID-19 acquired from a secondary transmission in Vietnam. Lancet Child Adolesc Health 2020;S2352-4642(20)30091-2 (e-pub ahead of print). Doi: 10.1016/S2352-4642(20)30091-2

39 Li W, Cui H, Li K, Fang Y, Li S. Chest computed tomography in children with COVID-19 respiratory infection. Pediatr Radiol 2020 (e-pub ahead of print). Doi: 10.1007/s00247-020-04656-7

$40 \mathrm{Lu} \mathrm{X}$, Zhang L, Du H, et al. SARS-CoV-2 Infection in Children. N Eng J Med 2020 (e-pub ahead of print). Doi: 10.1056/NEJMc2005073

41 Qiu H, Wu J, Hong L, Luo Y, Song Q Chen D. Clinical and epidemiological features of 36 children with coronavirus disease 2019 (COVID-19) in Zhejiang, China: an observational cohort study. Lancet Infect Dis 2020;S1473-3099(20)30198-5 (e-pub ahead of print). Doi: 10.1016/S1473-3099(20)30198-5

42 Su L, Ma X, Yu H, et al. The different clinical characteristics of corona virus disease cases between children and their families in China - the character of children with COVID-19. Emerg Microbes Infect 2020;9(01):707-713

43 Wei M, Yuan J, Liu Y, Fu T, Yu X, Zhang Z-J. Novel Coronavirus Infection in Hospitalized Infants Under 1 Year of Age in China. JAMA 2020;323(14):1313-1314 (e-pub ahead of print). Doi: 10.1001/jama.2020.2131

44 Xia W, Shao J, Guo Y, Peng X, Li Z, Hu D. Clinical and CT features in pediatric patients with COVID-19 infection: different points from adults. Pediatr Pulmonol 2020;55(05):1169-1174

45 Zeng LK, Tao XW, Yuan WH, Wang J, Liu X, Liu ZS. [First case of neonate infected with novel coronavirus pneumonia in China] (in Chinese). Zhonghua Er Ke Za Zhi 2020;58(00):E009

46 Zhang YH, Lin DJ, Xiao MF, et al. [2019-novel coronavirus infection in a three-month-old baby] (in Chinese). Zhonghua Er Ke Za Zhi 2020;58(00):E006

47 Molloy EJ, Bearer CF. COVID-19 in children and altered inflammatory responses. Pediatr Res 2020 (e-pub ahead of print). Doi: 10.1038/s41390-020-0881-y

48 Auriti C, Tzialla C, Giuffrè M, Manzoni P. What do we know about SARS-CoV-2 infection in neonates and infants? The Neonatal Infectious Diseases Collaborative Group of the Italian Society of Neonatology. SIN Informa Magazine of the Italian Society of Neonatology 2020, April issue (e-pub ahead of print). Availabe at: https://www.sin-neonatologia.it/. Accessed April 27, 2020

49 De Luca D, van Kaam AH, Tingay DG, et al. The Montreux definition of neonatal ARDS: biological and clinical background behind the description of a new entity. Lancet Respir Med 2017;5 (08):657-666

50 American Academy of Pediatrics \& American Heart Association; Weiner GM, Zaichkin J, eds. Textbook of Neonatal Resuscitation (NRP) 7th ed. Itasca, IL: American Academy of Pediatrics; 2016

51 Ferioli M, Cisternino C, Leo V, Pisani L, Palange P, Nava S. Protecting healthcare workers from SARS-CoV-2 infection: practical indications. Eur Respir Rev 2020;29(155):200068

52 Infection prevention and control of epidemic- and pandemicprone acute respiratory infections in health care. Available at: https://apps.who.int/iris/bitstream/handle/10665/112656/ 9789241507134_eng.pdf. Accessed April 21, 2020

53 Tran K, Cimon K, Severn M, Pessoa-Silva CL, Conly J. Aerosol generating procedures and risk of transmission of acute respiratory infections to healthcare workers: a systematic review. PLoS One 2012;7(04):e35797

54 Thompson KA, Pappachan JV, Bennett AM, et al; EASE Study Consortium. Influenza aerosols in UK hospitals during the H1N1 (2009) pandemic-the risk of aerosol generation during medical procedures. PLoS One 2013;8(02):e56278

55 Chan MTV, Chow BK, Lo T, et al. Exhaled air dispersion during bagmask ventilation and sputum suctioning - Implications for infection control. Sci Rep 2018;8(01):198

56 Chan MT, Chow BK, Chu L, Hui DS. Mask ventilation and dispersion of exhaled air. Am J Respir Crit Care Med 2013;187(07): e12-e14 
57 Hui DS, Hall SD, Chan MTV, et al. Noninvasive positive-pressure ventilation: An experimental model to assess air and particle dispersion. Chest 2006;130(03):730-740

58 Hui DS. Non-invasive Mechanical Ventilation: Models to Assess Air and Particle Dispersion. In: Esquinas AM, ed. Non-invasive Ventilation in High-Risk Infections and Mass Casualty Events. 1st ed. Vienna, Austria: Springer; 2014:7-16

59 Simonds AK, Hanak A, Chatwin M, et al. Evaluation of droplet dispersion during non-invasive ventilation, oxygen therapy, nebuliser treatment and chest physiotherapy in clinical practice: implications for management of pandemic influenza and other airborne infections. Health Technol Assess 2010;14(46): 131-172

60 Hui DS, Chow BK, Ng SS, et al. Exhaled air dispersion distances during noninvasive ventilation via different Respironics face masks. Chest 2009;136(04):998-1005

61 Hui DS, Chow BK, Chu L, et al. Exhaled air dispersion and removal is influenced by isolation room size and ventilation settings during oxygen delivery via nasal cannula. Respirology 2011;16 (06):1005-1013 